\title{
Influence of Maternal Preeclampsia on Neurodevelopmental Outcomes of Preterm Infants
}

\author{
Halil DEGIRMENCIOGLU1, Birgul SAY², Zeynep ERAS 3 , Serife Suna OGUZ4 \\ Aydin, Turkey
}

\begin{abstract}
OBJECTIVE: The aim of this study was to determine the neurodevelopmental outcome of preterm infants born to mothers with preeclampsia and to compare them with preterm controls.

STUDY DESIGN: This was a retrospective, observational study in a large, tertiary, neonatal intensive care unit. Neurodevelopmental evaluations using Bayley Scales of Infant Development II were performed in 226 two-year-old infants with birth weight $\leq 1500 \mathrm{~g}$ and gestational age $\leq 32$ weeks who were born to mothers with preeclampsia and in 493 infants who were born after normotensive pregnancies, matched for gestational age and gender.

RESULTS: The mean gestational ages of the infants in the preeclampsia and control groups were $29.9 \pm 2.3$ weeks and $28.7 \pm 4.1$ weeks, respectively $(p<0.001)$. A total of 372 infants with a mean age of $19.2 \pm 3.2$ months were assessed for long-term outcome. The mean mental developmental index score was significantly higher, and the percentage of infants with cerebral palsy was significantly lower, in the preeclampsia group compared with the control group ( $p=0.03$ and $p=0.02$, respectively). However, no overall significant differences in neurodevelopmental impairment rates were found between the two groups $(p=0.08)$.
\end{abstract}

CONCLUSION: Maternal preeclampsia seems to be a protector factor for the development of cerebral palsy in preterm infants.

Keywords: Preeclampsia, Neurodevelopmental outcome, Preterm infant

Gynecol Obstet Reprod Med 2018;24(2):99-103

\section{Introduction}

In recent decades, advances in perinatal and neonatal care have led to an improved survival rate among preterm infants. However, the rates of major short- and long-term morbidities have not changed (1). Several prenatal (preeclampsia, gestational diabetes, chorioamnionitis) and postnatal (respiratory

${ }^{1}$ Division of Neonatology Aydin Maternity and Teaching Hospital, Aydin ${ }^{2}$ Division of Neonatology University of Health Sciences Derince Education and Research Hospital, Kocaeli

${ }^{3}$ Developmental Behavioral Pediatrics Unit University of Health Sciences Zekai Tahir Burak Maternity Teaching Hospital, Ankara

Address of Correspondence: Birgul Say

Division of Neonatology, Derince

Education and Research Hospital,

41380 Kocaeli, Turkey

birgullivasay@gmail.com

Submitted for Publication: $\quad 20.09 .2017$

Accepted for Publication: $\quad 17.03 .2018$

\begin{tabular}{|c|c|}
\hline \multicolumn{1}{|c|}{ Access this article online } \\
\hline Quick Response Code: & $\begin{array}{c}\text { Website: www.gorm.com.tr } \\
\text { e-mail: info@gorm.com.tr }\end{array}$ \\
\cline { 2 - 3 } & DOI:10.201613/GORM.2018.737 \\
\hline
\end{tabular}

How to cite this article: Degirmencioglu H. Say B. Eras Z. Oguz SS. Influence of Maternal Preeclampsia on Neurodevelopmental Outcomes of Preterm Infants. Gynecol Obstet Reprod Med 2018;24(2):99-103 distress syndrome (RDS), sepsis, patent ductus arteriosus (PDA), necrotizing enterocolitis (NEC), intraventricular hemorrhage (IVH), bronchopulmonary dysplasia (BPD) factors have been linked to impaired neurodevelopment outcome $(2,3)$.

Maternal preeclampsia is a heterogeneous disorder that complicates $2-8 \%$ of pregnancies and is a major cause of mortality and morbidity in both mothers and infants $(4,5)$. Neonatal outcomes in infants born to preeclamptic mothers are primarily associated with severity of prematurity and brief duration of pregnancy (4). Gestational age at the time of delivery has been shown to be the main prognostic factor for neonatal mortality and adverse neonatal outcomes (6).

Recent available data on long-term outcomes in preterm infants exposed to preeclampsia in utero are highly variable (7). Some studies demonstrated that preeclampsia has a great impact on mental developmental $(4,8)$, while other studies suggested that infants born to preeclamptic mothers had higher developmental testing scores at 18 months corrected age (9) and a decreased risk of cerebral palsy (5). These data obviously indicate that conflicting results regarding adverse neurodevelopmental outcome in infants exposed to maternal preeclampsia still exist. Therefore, we conducted a retrospective case-control study to evaluate both short- and long-term outcomes in infants (birth weight $\leq 1500 \mathrm{~g}$ and gestational age 
$\leq 32$ weeks) born to mothers with preeclampsia and in infants born to control mothers, regardless of exposure to magnesium sulfate during pregnancy.

\section{Material and Method}

\section{Study Population}

This retrospective, single-center study was conducted in the neonatal intensive care unit of Zekai Tahir Burak Maternity Teaching Hospital, Ankara, Turkey, from January 2008 to November 2013. All preterm infants with a gestational age $\leq 32$ weeks and birth weight $\leq 1500 \mathrm{~g}$ born to mothers with preeclampsia without any other coexisting medical conditions were included and compared with infants born after normotensive pregnancies and matched for gestation, gender, and survival. Subjects with other maternal conditions affecting neurological outcome, such as chorioamnionitis, death, prolonged rupture of membranes, diabetes mellitus, intrauterine growth retardation and infants with major congenital malformations, were excluded from the study.

Two groups were defined: i) infants exposed to maternal preeclampsia (study group) and ii) control infants born to normotensive mothers and matched for gestational age and gender. The medical records of both mothers and newborns, including parental, medical, demographic, and obstetric details, were extracted from the hospital records by the researchers.

Preeclampsia was defined as blood pressure $140 / 90 \mathrm{mmHg}$ accompanied by proteinuria level $\geq 300 \mathrm{mg} / 24 \mathrm{~h}$ after 20 weeks of gestation (3). Gestational age was evaluated by maternal dates and confirmed by the modified Ballard examination (10).

Neurodevelopmental outcomes at 18 to 24 months' corrected age were evaluated with neurologic exams and Bayley Scales of Infant Development II. A comprehensive evaluation, including neurological examination, vision and hearing examination, and developmental assessment using Bayley Scales of Infant Development II, were performed by experienced examiners.

Written informed consent for the study was obtained from a parent or guardian of each infant, and the study protocol was approved by the local ethics committee of Zekai Tahir Burak Maternity Teaching Hospital.

\section{Definition of outcome variables}

Neurodevelopmental impairment (NDI) was defined as the presence of one or more of the following events: (1) cerebral palsy (CP) with functional deficits, (2) bilateral hearing loss and/or blindness, and (11) mental developmental index (MDI) and/or psychomotor developmental index (PDI) $<70$ ( $>2$ standard deviations below a mean of $100)$. CP was defined as a non-progressive motor disorder with abnormal muscle tone in at least one extremity and abnormal control of movement and posture (12). Infants who were severely impaired and not able to complete the test were assigned an MDI or PDI score of 49.

\section{Statistical analysis}

A descriptive analysis of the demographic and clinical characteristics of the patients was conducted. Student's t-test or the MannWhitney U test was used for comparison of numeric variables between the two groups. The chi-square test was used to compare ratios between the two groups. Binary logistic regression analysis was used to conduct a multivariate analysis of factors associated with neurodevelopmental outcome. The statistical analyses were performed with SPSS software version 17.0 (SPSS Inc., Chicago, IL), and statistical significance was set at $p<0.05$.

\section{RESULTS}

\section{Baseline characteristics}

Between March 2008 and January 2012, 1120 infants were assessed for eligibility in the trial. A total of 719 infants met the inclusion criteria. The study group consisted of 226 premature infants born to mothers with preeclampsia, and the control group consisted of 493 premature infants born to normotensive mothers. Figure 1 shows the flow chart for the study group. Baseline demographic characteristics of the groups are summarized in table 1. Mean gestational age of the infants in the preeclampsia and control groups were $29.9 \pm 2.3$ weeks and $28.7 \pm 4$.1 weeks, respectively; the difference was statistically significant $(p<0.001)$. The mean birth weights did not differ significantly between the groups $(1117 \pm 267 \mathrm{~g}$ and $1121 \pm 296 \mathrm{~g}$, respectively; $p=0.8)$.

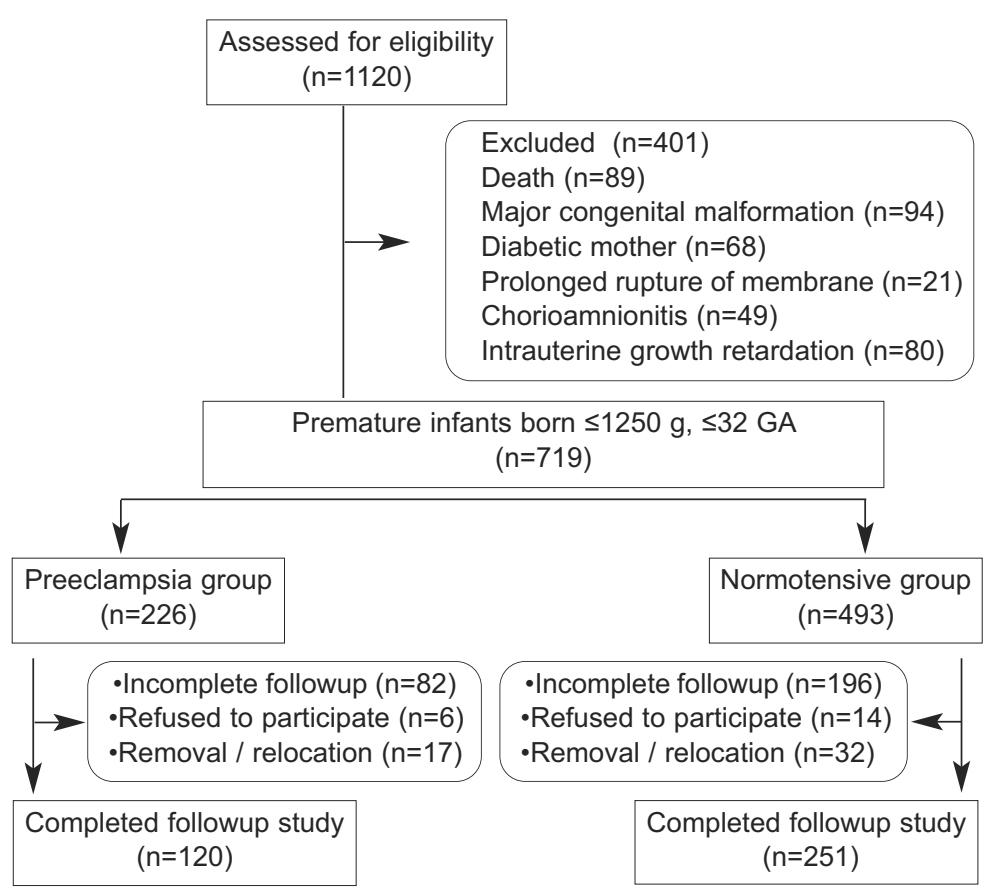

Figure 1: Flowchart of the study group 
No significant differences were found between the two groups in postnatal risk factors such as low Apgar score, duration of mechanical ventilation, RDS, PDA, severe IVH, hypoglycemia, polycythemia, and BPD.

\section{Neurodevelopmental outcomes}

During the study period, 106 (47\%) of the 226 infants in the preeclampsia group and $242(49 \%)$ of the 493 infants in the control group were excluded due to incomplete follow-up, refusal to participate, or relocation. A total of 371 premature infants were assessed at 18-24 months CA for the neurodevelopmental. Of those patients, 120 were in the preeclampsia group and 251 were in the control group. Neurodevelopmental assessment was performed at a mean age of 19.2 \pm 3.2 months CA.
Data of the demographic and neurodevelopmental outcomes at two years of age are shown in table 2. No significant differences were found between the groups in variables such as gestational age, birth weight, asphyxia, sepsis, hypothyroidism, severe IVH, and severe NEC.

The preeclampsia group had significantly higher MDI scores $(89.7 \pm 19.7)$ compared to the control group (84.6 \pm 21.6$)$ $(p=0.03)$. The mean PDI scores were $84.6 \pm 20.6$ in the preeclampsia group and $82.4 \pm 21.9$ in the control group; the difference was not significant $(p=0.35)$. Cerebral palsy was present in seven $(6 \%)$ of the 120 infants in the preeclampsia group and in 34 (14\%) of the 251 infants in the control group; the preeclampsia group had a significantly lower rate

Table 1: Baseline characteristics of infants

\begin{tabular}{|c|c|c|c|}
\hline Variable & $\begin{array}{l}P E \\
(n=226)\end{array}$ & $\begin{array}{l}\text { No PE } \\
(n=493)\end{array}$ & $\begin{array}{l}\mathrm{p} \\
\text { value }\end{array}$ \\
\hline Gestational age, weeks ${ }^{a}$ & $29.9 \pm 2.3$ & $28.7 \pm 4.1$ & $p<0.001$ \\
\hline Birth weight, $g^{a}$ & $1117 \pm 267$ & $1121 \pm 296$ & 0.80 \\
\hline Gender (male) ${ }^{\mathrm{b}}$ & $101(44)$ & $290(59)$ & 0.12 \\
\hline Low Apgar score $(5 \min <5)^{b}$ & $34(15)$ & $79(16)$ & 0.08 \\
\hline Duration of mechanical ventilation (days) & $5.3 \pm 10$ & $6.2 \pm 16$ & 0.4 \\
\hline RDS, use of surfactant ${ }^{b}$ & $129(57)$ & $245(49)$ & 0.12 \\
\hline $\mathrm{PDA}^{\mathrm{b}}$ & $51(22)$ & $134(25)$ & 0.27 \\
\hline Severe $\mathrm{IVH}^{\mathrm{c}}, \mathrm{n}$ & 6 & 14 & 0.18 \\
\hline Hypoglycemia, n & 13 & 25 & 0.1 \\
\hline Polycythemia, n & 26 & 50 & 0.1 \\
\hline BPD, $\mathrm{n}$ & 24 & 51 & 0.618 \\
\hline
\end{tabular}

a: Mean $\pm S D, b: n(\%)$, c: Severe was defined as grade 3 or 4 intraventricular hemorrhage using the criteria of Papile15, RDS: Respiratory distress syndrome, PDA: Patent ductus arteriosus, BPD: Bronchopulmonary dysplasia

Table 2: Analysis of neurodevelopmental outcomes at 18-24 months corrected age (CA)

\begin{tabular}{|c|c|c|c|}
\hline Variables & $\begin{array}{l}P E \\
(n=120)\end{array}$ & $\begin{array}{l}\text { No PE } \\
(n=251)\end{array}$ & $\mathrm{p}^{*}$ \\
\hline BBirth weight, $\mathrm{g}^{\mathrm{a}}$ & $1124 \pm 228$ & $1124 \pm 253$ & 0.06 \\
\hline Gestational age, week ${ }^{a}$ & $29.6 \pm 1.9$ & $29.2 \pm 1.8$ & 0.93 \\
\hline Asphyxia, $\mathrm{n}$ & 0 & 2 & 0.45 \\
\hline Sepsis ${ }^{b}$ & $58(48)$ & $125(49.8)$ & 0.42 \\
\hline Hypothyroidismb & $5(0.04)$ & $16(0.06)$ & 0.27 \\
\hline IVH, Grade 3-4, n & 3 & 10 & 0.44 \\
\hline \multirow[t]{2}{*}{ NEC, Stage $3-4, n$} & 0 & 6 & 0.05 \\
\hline & Iopmental & & \\
\hline$N D I^{b}$ & $102(59.3)$ & $102(59.3)$ & 0.08 \\
\hline $\mathrm{MDI}^{\mathrm{a}}$ & $89.7 \pm 19.7$ & $84.6 \pm 21.6$ & 0.03 \\
\hline PDIa & $84.6 \pm 20.6$ & $82.4 \pm 21.9$ & 0.35 \\
\hline $\mathrm{MDI}<70^{\mathrm{b}}$ & $25(21)$ & $65(26)$ & 0.29 \\
\hline $\mathrm{PDI}<70^{\mathrm{b}}$ & $36(30)$ & $76(30)$ & 0.36 \\
\hline $\mathrm{CP}, \mathrm{n}$ & 7 & 34 & 0.02 \\
\hline Bilateral deafness, $n$ & 0 & 1 & 0.52 \\
\hline Bilateral blindness, $\mathrm{n}$ & 0 & 0 & - \\
\hline
\end{tabular}

a: Mean \pm SD, b: $n(\%), P E:$ Preeclampsia, IVH: Intraventricular hemorrhage, NEC: Necrotizing enterocolitis, NDI: Neurodevelopmental impairment, MDI: Mental developmental index, PDI: Psychomotor developmental index, CP: Cerebral palsy 
$(p=0.02)$. This difference was confirmed in the multiple logistic regression model; in which it was found that preeclampsia was a possible factor protecting the infants from $\mathrm{CP}$ $(\mathrm{OR}=0.39 ; 95 \%$ confidence interval $(\mathrm{CI}): 0.17-0.91)$. Overall, however, no statistically significant difference in NDI was found between the groups ( $p=0.08)$, confirmed by multiple logistic regression analysis $(\mathrm{OR}=1.44$; $\mathrm{CI}$ : 0.91-2.27).

\section{Discussion}

In this study, we report on a relatively large study population with long-term data of approximately $50 \%$ of the surviving infants of both groups. The results of this study suggested that maternal preeclampsia might have a positive impact on the neurodevelopmental outcome of preterm infants.

Maternal preeclampsia seems to be a protector factor for the development of cerebral palsy in preterm infants, (8). Preeclampsia is not a uniform disease, and it can range from a subacute or chronic course to acute disease with sudden deterioration of the placenta-fetal blood supply. Although the hemodynamic effects of preeclampsia can be partly reduced by fetal compensatory mechanisms, even moderate preeclampsia exposes the fetus to placental insufficiency, which can lead to intrauterine ischemic brain damage (3).

Studies on the outcome of infants born to mothers with preeclampsia have yielded conflicting results. Some studies have suggested that maternal preeclampsia is associated with significant developmental delays in gross motor, fine motor, and visual motor functions in early childhood $(13,14)$. Taylor et al. found strong associations between all categories of disability, with the exception of $\mathrm{CP}$, and severe hypertension or preeclampsia during pregnancy (15). Szymonowicz and $\mathrm{Yu}$ found that the developmental index at the age of two years was not different, but that the mean MDI was significantly lower and the incidence of CP was higher in infants born to mothers with preeclampsia (16). Many et al. reported that newborns born after pregnancies complicated by preeclampsia have lower IQs at three years of age compared to babies born to mothers without preeclampsia (13). In a study conducted in Sweden, preeclampsia was associated with a high risk of $\mathrm{CP}$ (OR 1.5, 95\% CI 1.3-2.4) (17).

Some studies have suggested that preeclampsia has no negative impact on long-term outcomes. Seidman et al. found no differences between the IQ scores of infants born to mothers with and without preeclampsia (18). Schlapbach et al. compared the neurodevelopmental outcomes of infants born at $<32$ weeks' gestational age after maternal preeclampsia or chorioamnionitis and those of controls, and they concluded that chorioamnionitis and preeclampsia exposure were not associated with major neurodevelopmental impairments (CP, MDI <70, PDI <70) (20).

Some evidence suggests that preeclampsia is associated with a decreased risk of $\mathrm{CP}$. Gray et al. found that maternal preeclampsia has a protective effect on $\mathrm{CP}$ in infants born at $\leq 32$ weeks' gestation, regardless of exposure to magnesium sulfate (21). Xiong et al. performed a meta-analysis and reported that preeclampsia was associated with a statistically significantly decreased risk of CP in preterm and low birth weight infants [pooled adjusted $\mathrm{OR}=0.50 ; 95 \% \mathrm{CI}$ : 0.33-0.81; $\mathrm{p}<0.01)$. Silveira at al. reported better neurodevelopment outcomes at 18 months $\mathrm{CA}$ in infants delivered by preeclamptic mothers than in controls (9).

In our study, although overall NDI rates did not differ significantly between the two groups, MDI scores were higher and $\mathrm{CP}$ rates were lower in the preeclampsia group. The odds of CP for preterm infants, was 0.39 times lower with preeclampsia present than without, which is similar to results found in other analyses $(21,22,23)$.

The potential causes of such differences are not clear. One possible explanation is that the cumulative in utero and postnatal factors probably have a higher impact on these high-risk infants. Secondly, we already know that antenatal maternal treatment with magnesium sulfate can improve the neurodevelopmental outcomes of premature infants $(23,24)$. However, because mothers with high-risk pregnancies are routinely supplemented with magnesium sulfate in our hospital, we could not assess the extent to which this factor affected outcome.

One of our limitations is that the study is not recorded in the treatment of mothers with preeclampsia $(\mathrm{Mg}$, etc.) and the other one is the small sample size.

In conclusion, we also observed a nonsignificant association between preeclampsia and developmental delay and neurodevelopmental impairment in very low birth weight preterm infants. Longer term neurodevelopmental outcomes for prematurely born infants are dependent on gestational age. Further studies are needed to confirm this continuous relationship between neurodevelopmental outcomes and preeclempsia.

: Acknowledgments: This study was conducted by the Zekai Tahir Burak Maternity Teaching Hospital Neonatology Department and Blood Center Department. H.D., B.S., and Z.U., made substantial contributions to the study design and data collection, as well as critically revising the manuscript. S.S.O., supported the data collection and critically revised the manuscript.

Conflict of Interest: The authors have no competing interests Funding: No foundation

\section{References}

1. Fanaroff AA, Stoll BJ, Wright LL, et al. Trends in neonatal morbidity and mortality for very low birthweight infants. Am J Obstet Gynecol 2007 Feb;196(2):147.1-8.

2. Latal B. Prediction of neurodevelopmental outcome after preterm birth. Pediatr Neurol 2009 Jun;40(6):413-9 
3. Sibai B, Dekker G, Kupferminc M. Pre-eclampsia. Lancet 2005 Feb; 365(9461):785-99

4. Cheng SW, Chou HC, Tsou KI, Fang LJ, Tsao PN. Delivery before 32 weeks of gestation for maternal preeclampsia: neonatal outcome and 2-year developmental outcome. Early Hum Dev 2004 Jan;76(1):39-46.

5. Gray PH, O’Callaghan MJ, Mohay HA, Burns YR, King JF. Maternal hypertension and neurodevelopmental outcome in very preterm infants. Arch Dis Child Fetal Neonatal Ed 1998 Sep;79(2):88-93.

6. Derham RJ, Hawkins DF, de Vries LS, Aber VR, Elder MG. Outcome of pregnancies complicated by severe hypertension and delivered before 34 weeks; stepwise logistic regression analysis of prognostic factors. Br J Obstet Gynaecol 1989 Oct; 96(10):1173-81.

7. Shah DM, Shenai JP, Vaughn WK. Neonatal outcome of premature infants of mothers with preeclampsia. J Perinatol 1995 Jul-Aug;15(4):264-7.

8. Many A, Fattal A, Leitner Y, Kupferminc MJ, Harel S, Jaffa A. Neurodevelopmental and cognitive assessment of children born growth restricted to mothers with and without preeclampsia. Hypertens Pregnancy 2003;22(1):25-9.

9. Silveira RC, Procianoy RS, Koch MS, Benjamin AC, Schlindwein CF. Growth and neurodevelopment outcome of very low birth weight infants delivered by preeclamptic mothers. Acta Paediatr 2007 Dec;96(12):1738-42.

10. Ballard JL, Khoury JC, Wedig K, Wang L, EilersWalsman BL, Lipp R. New Ballard Score, expanded to include extremely premature infants. J Pediatr 1991 Sep;119(3):417-23.

11. Wu YW, Colford JM Jr. Chorioamnionitis as a risk factor for cerebral palsy: a meta-analysis. JAMA 2000 Sep; 284(11):1417-24.

12. Bayley N. Bayley Scales of Infant Development II. San Antonio: Psychological Corp; 1993.

13. Ounsted MK, Moar VA, Good FJ, Redman CW.
Hypertension during pregnancy with and without specific treatment; the development of the children at the age of four years. Br J Obstet Gynaecol 1980 Jan;87(1):19-24.

14. International Committee for the Classification of Retinopathy of Prematurity. The International Classification of Retinopathy of Prematurity revisited. Arch Ophthalmol 2005 Jul;123(7):991-9.

15. Taylor DJ, Howie PW, Davidson J, Davidson D, Drillien CM. Do pregnancy complications contribute to neurodevelopmental disability? Lancet 1985 Mar;1(8431):713-6.

16. Szymonowicz W, Yu VY. Severe pre-eclampsia and infants of very low birth weight. Arch Dis Child 1987 Jul;62(7):712-6.

17. Thorngren-Jerneck K, Herbst A. Perinatal factors associated with cerebral palsy in children born in Sweden. Obstet Gynaecol 2006 Dec;108(6):1499-505.

18. Seidman DS, Laor A, Gale R, Stevenson DK, Mashiach S, Danon YL. Pre-eclampsia and offspring's blood pressure, cognitive ability and physical development at 17 years of age. Br J Obstet Gynaecol 1991 Oct; 98(10):1009-14.

19. Schlapbach LJ, Ersch J, Adams M, Bernet V, Bucher HU, Latal B. Impact of chorioamnionitis and preeclampsia on neurodevelopmental outcome in preterm infants below 32 weeks gestational age. Acta Paediatr 2010 Oct;99 (10): 1504-9.

20. Gray PH, O’Callaghan MJ, Mohay HA, Burns YR, King JF. Maternal hypertension and neurodevelopmental outcome in very preterm infants. Arch Dis Child Fetal Neonatal Ed 1998 Sep;79(2): F88-93.

21. Spinillo A, Capuzzo E, Cavallini A, Stronati M, De Santolo A, Fazzi E. Preeclampsia, preterm delivery and infant cerebral palsy. Eur J Obstet Gynecol Reprod Biol 1998 Apr;77(2):151-5.

22. Xiong X, Saunders LD, Wang FL, Davidge ST, Buekens P. Preeclampsia and cerebral palsy in low-birth-weight and preterm infants: implications for the current "ischemic 